\title{
A visibilidade da profissão de enfermeiro: reconhecendo conQuistas e lacunas
}

\author{
The visibility of nurse as a profession: recognizing conquests and gaps \\ La visibilidad de la profesión de enfermero: reconociendo logros y vacíos
}

\begin{abstract}
Alacoeue Lorenzini Erdmann', Juliana Vieira Fernandes', Cecília Melo', Bruna Ré Carvalho', Quézia Menezes', Roberta de Freitas', Eduardo Emarinony', Marli Terezinha Stein Backes'

'Universidade Federal de Santa Catarina. Departamento de Enfermagem, Programa de Pós-Graduação em Enfermagem, Grupo de Estudos e Pesquisas em Administração em Enfermagem. Florianópolis, SC
\end{abstract}

Submissão: $18 / 08 / 2009$

Aprovação: 22/07/2009

\section{RESUMO}

Este relato de experiência objetivou refletir e discutir sobre as conQuistas e lacunas Que refletem na visibilidade da profissão do enfermeiro/ enfermagem. Foi construído no transcorrer da Disciplina Optativa do Curso de Graduação em Enfermagem: "Mercado de Trabalho em Enfermagem e novas modalidades de prestação de serviço". Os acadêmicos vêem o Enfermeiro como sendo um profissional voltado para o cuidado. As categorias que emergiram dos dados referente à visão dos acadêmicos de enfermagem em relação ao profisional enfermeiro, ao serem formandos são: avanços e conQuistas, satisfação profissional e lacunas na profissão. É importante desenvolver a competência política com visão ampliada da profissão de enfermagem exercitando o cuidado empreendedor como um compromisso social de cidadania na conQuista do viver com mais saúde.

Descritores: Enfermagem; Mercado de trabalho; Papel do profissional de enfermagem; Competência profissional.

\section{ABSTRACT}

This experience report aimed at discussing and reflecting about undergraduate classes, literature and discussions conducted in seminaries with nursing students, the conquests and the gaps that are reflected in the visibility of the nursing profession. The "Job market in Nursing and new modalities of rendering services". The students see the Nurse as a professional focused on care. The categories that emerged from the data referring to the nursing students' view just before graduating are: advances and conquests, professional satisfaction and gaps in the profession. It is important to develop the political competence with a broadened view of the nursing profession as a social compromise of citizenship in the coneuest of living more healthly.

Descriptors: Nursing; Job market; Nurse's role; Professional competence.

\section{RESUMEM}

Se apuntó a reflexionar y discutir sobre los logros y vacíos Que refleja la visibilidad de la profesión de enfermería. Se construyó durante la Disciplina Optativa del Curso de Graduación en Enfermería: "Mercado del trabajo en Enfermería y nuevas modalidades de prestación de servicio". Los académicos ven al enfermero regresando al cuidado. Las categorías Que surgieron según la visión de los académicos respecto al profesional de enfermería fueron: avances y logros, satisfacción profesional y vacíos en la profesión. Es importante desarrollar la competencia política con visión de la profesión de enfermería dando cuidado como un compromiso social de ciudadanía en la conQuista de vivir con más salud.

Descriptores: Enfermería; Mercado de trabajo; Rol de la enfermera; competencia profesional. 


\section{INTRODUÇÃO}

No século XX, Joseph Schumpeter, a partir dos estudos de Richard Cantillon, conhecido como o primeiro grande teórico economista, definiu a função do empreendedor. Para Schumpeter o empreendedor pode ser definido como: "criador de novas combinações; alguém Que tem a habilidade para Que o novo seja implementado". Em outras palavras, empreendedor é aquele Que realiza coisas novas e, não necessariamente, aquele Que inventa. Ele faz coisas Que não são geralmente feitas em vias normais na rotina de negócio ${ }^{(1)}$.

O empreendedorismo se enquadra na conduta ativa do profissional em primeiro desvencilhar-se do pensamento e conduta retrógrados da limitação de pensamentos e ações, captar deficiências não solucionadas em suas áreas, criar técnicas eficientes e efetivas ou utilizar as já existentes de forma inovadora para a solução das deficiências. Aproveita todas as oportunidades coletivamente, vislumbrando a conquista de ganhos substanciais, profissionalmente e socialmente.

Assim, a lógica do empreendedorismo é iniciada com a identificação das oportunidades de negócio Que ofereçam a realização de novas ações, sem Que para isso sejam realizados inventos ou avanços tecnológicos espetaculares. O mais importante é a capacidade de perceber o que nenhum outro viu, atribuindo ações promissoras.

A Enfermagem como profissão tem caminhado, por meio de estudos e pesquisas, para a formação de um corpo teórico próprio Que a visibilize e projete como ciência. As pesquisas e os campos de atuação na enfermagem têm crescido substancialmente nos últimos anos, abrindo perspectivas de conhecimento em múltiplas direções e espaços.

Estudos mais recentes evidenciam Que a visibilidade do enfermeiro implica na articulação de competências com evidências a nível técnico, científico e relacional, o Que concorre para a representação social da profissão. O status profissional constrói-se a partir das atitudes individuais Que formam o coletivo e que, por sua vez, se refletem na ampliação das intervenções sociais, mais expressivamente, na ocupação de espaços Que dêem margem e reconhecimento à enfermagem como protagonista de um novo saber e fazer ${ }^{(2,3)}$

Outros trabalhos buscaram averiguar nos diferentes estratos da população, a representação e a invisibilidade do profissional enfermeiro. Entre outros aspectos, os resultados evidenciaram Que a visibilidade do enfermeiro está associada, apesar de todos os avanços e conQuistas, às tarefas técnicas, como subordinado à área médica ou auxiliar de médico, relacionando a atuação profissional com mão-de-obra barata ${ }^{(4)}$.

Não obstante, outra pesQuisa avaliou se a exposição a uma mediação pela internet, Que explorasse papéis e campos de atuação do enfermeiro no Brasil hoje, poderia influenciar na construção da representação social Que estudantes do ensino médio têm do enfermeiro e da enfermagem. Os resultados mostram duas categorias de representação: o "antes" e o "agora", conforme segue a reflexão: "antes", viam o enfermeiro como auxiliar de médico, sem importância, subalterno; desconheciam Que o enfermeiro tivesse conhecimentos aprofundados. Consideravam Que a atuação era somente hospitalar, auxiliando paciente e médico, fazendo atividades "mais sujas" e árduas. "Agora" associam o enfermeiro à imagem de um médico, "fazem o papel de médico", prescrevem, coordenam, e Que esta profissão pode ser autônoma. Identificam Que o enfermeiro pode ser especialista em diferentes campos e especialidades, até "chefes de médico". Associam as ações de decisão, coordenação, avaliação clínica, diagnóstico e intervenção de enfermagem como atributos de independência e conhecimento cristalizados no imaginário social como do médico. Percebem a ação do enfermeiro na educação e pesQuisa em diversos níveis de atuação. Surpreendem-se Que o enfermeiro realize consultas de enfermagem de forma independente ${ }^{(5)}$.

Investigações mais recentes objetivaram compreender o "significado do cuidado de enfermagem como prática social empreendedora" evidenciando Que o enfermeiro possui múltiplos espaços de atuação profissional, bem como potencialidades e possibilidades específicas para desenvolver processos interativos e associativos no âmbito das políticas sociais e de saúde. O enfermeiro possui, em outras palavras, um "leque de possibilidades amplo e complexo para desenvolver o cuidado de enfermagem como prática social. Possui um campo aberto nos diferentes espaços e contextos, contudo, esses necessitam gradativamente serem explorados e ampliados", a fim de responder e visibilizar de forma concreta e abrangente às Questões sociais emergentes ${ }^{(6)}$.

No campo da enfermagem, os avanços e práticas de atuação profissional podem ser evidenciados nos diferentes contextos sociais, conforme apontam os autores anteriormente elucidados. Nessa direção, destacam-se: na esfera da promoção da saúde - os consultórios, as clínicas e serviços Que visam a promoção e o melhorviver da população; na esfera da recuperação da saúde - os serviços hospitalares e domiciliares, o atendimento pré e pós-hospitalar, além das práticas voltadas para o cuidado individual de crianças, adolescentes, mulheres, adultos e idosos; o terceiro setor - mesmo Que considerado promissor, se mostra como um espaço sensível para a promoção da cidadania e a inclusão social por meio da promoção e educação para a saúde; Nos serviços de consultoria, assessoria e atividades organizacionais - é possibilitado ao enfermeiro uma atuação autônoma e empreendedora no campo da gestão de serviços de saúde e outros; nas atividades de ensino e pesquisa - o estímulo à inserção dos alunos e profissionais nos grupos de pesquisa, projetos de extensão e uma interação aluno-comunidade mais intensa e otimizada $^{(7)}$.

Em conformidade com o exposto, acreditamos Que Questões referentes ao empreendedorismo precisam ser despertadas desde a graduação, para Que os futuros enfermeiros tenham uma visão ampliada dos espaços de atuação Que a enfermagem possui e não se limitem a atuar apenas em locais institucionalizados.

Com o propósito de acrescentar novas idéias à formação do enfermeiro, é Que se deu início, no segundo semestre de 2007, à Disciplina Optativa - Mercado de Trabalho em Enfermagem e novas modalidades de prestação de serviço, no Departamento de Enfermagem da Universidade Federal de Santa Catarina (UFSC). Além de levantar as possibilidades de mercado de trabalho da enfermagem/saúde e discutir os aspectos legais e organizacionais subjacentes a estas possibilidades, a ementa da disciplina objetiva, também, discutir novas modalidades de organização e cooperação dos serviços de enfermagem/saúde, a fim de criar ou inovar processos interativos, Que visibilizem as práticas e campos de 
atuação profissional do enfermeiro ${ }^{(8)}$.

Em consonância com os propósitos da disciplina em Questão, o presente trabalho tem por objetivo refletir e discutir, a partir das vivências na graduação, da literatura e discussões realizadas em seminários com os acadêmicos de enfermagem, as conQuistas e lacunas Que refletem na visibilidade do enfermeiro/enfermagem, despertando a visão empreendedora social do(a) enfermeiro(a) a partir da graduação.

\section{MÉTODO}

O estudo se caracteriza como relato de experiência, construído com um grupo de seis Acadêmicos de Enfermagem, dos Quais cinco são do sexo feminino e apenas um do sexo masculino, no transcorrer da Disciplina Optativa do Curso de Graduação em enfermagem da UFSC: "Mercado de Trabalho em Enfermagem e novas modalidades de prestação de serviço", ao longo do segundo semestre de 2008. As atividades foram organizadas e implementadas por uma doutoranda em "Estágio de Docência" sob a coordenação da Professora Responsável por esta disciplina. Este Curso de Graduação em Enfermagem trabalha com as metodologias ativas, baseadas na problematização e, para a elaboração deste artigo, foram realizados seminários de reflexão e discussões com este grupo de graduandos de enfermagem, desencadeadas a partir de visitas de observação realizadas a serviços autônomos de enfermagem e a um Projeto de Inclusão Social, bem como, por meio de artigos encontrados e selecionados na base de dados Bireme com o descritor: visibilidade do enfermeiro, além de outras referências pertinentes ao assunto.

Dentre os serviços de enfermagem visitados, conhecemos os seguintes nichos de trabalho: - consultoria e treinamento relacionados à saúde do trabalhador; - serviço especializado em podologia e comércio de produtos relacionados; - prestação de serviços e capacitação referente ao Diabetes Mellitus e suas implicações a uma cooperativa médica e à Secretaria Municipal da Saúde. Destacamos Que todos estes serviços citados são gerenciados por enfermeiros.

Os elementos observados nos serviços visitados e socializados nos seminários, além do relato do grupo de acadêmicos sobre a sua visão em relação ao profissional Enfermeiro ao ingressarem na graduação e atualmente, ao finalizarem o curso, serviram como subsídios para uma análise dos conceitos e características relevantes, criando categorias nucleadoras, caracterizadas por um conjunto de idéias, a fim de facilitar a compreensão e visibilidade do trabalho do enfermeiro/enfermagem ${ }^{(9)}$.

Para manter a originalidade de algumas idéias Que emergiram do relato da visão dos Acadêmicos em relação ao Profissional Enfermeiro, foram utilizados, no corpo do texto, alguns fragmentos da fala dos participantes, na íntegra. As falas dos sujeitos foram nomeadas com o nome de Acadêmico, seguido de um número. Vale aQui ressaltar Que a seQüência em Que aparece a relação dos Acadêmicos no Quadro I em anexo, não obedece a mesma ordem numérica em Que os Acadêmicos são citados como autores no presente artigo, para evitar identificá-los.

Lembramos Que este trabalho trata-se de um relato de experiência e, os próprios sujeitos do estudo também são autores do trabalho, sendo Que todos eles deram o seu consentimento para participar do estudo, bem como para divulgar os resultados.

\section{RESULTADOS E DISCUSSÃO}

O Quadro I representa a visão de um grupo de 06 (seis) Acadêmicos de Enfermagem do último semestre $\left(8^{\circ}\right)$ do Curso de Graduação em Enfermagem, de uma Universidade Pública Federal do Brasil, a respeito da idéia Que tiveram sobre o profissional Enfermeiro ao ingressarem na graduação, e atualmente, ao concluírem a graduação.

\section{A visão dos Acadêmicos a respeito do profissional Enfermeiro ao ingressarem na Graduação}

O Quadro I mostra Que a visão Que estes seis Acadêmicos de Enfermagem tinham ao ingressarem na graduação foi bastante semelhante, embora apresente algumas diferenças. Todos eles se referem à atuação do Enfermeiro como sendo um trabalho institucionalizado, especialmente atuando em hospitais e em Unidades Básicas de Saúde (UBS), trabalhando para outras pessoas, ou seja, sendo empregado nas instituições de saúde. Citaram também o trabalho realizado em Clínicas, Centros de Saúde e Home Care, demonstrando assim, de modo geral, um campo de atuação limitado. Por outro lado, estes acadêmicos, mesmo Quando ainda não conheciam a profissão, alegam Que o Enfermeiro "presta atendimento indispensável em saúde", "é um profissional cuidador", "pessoa Que cuida de outra, Que oferece carinho, conforto, apoio emocional”, “está muito próximo das pessoas e consequentemente cria um vínculo maior com pacientes e família".

A enfermagem como profissão assume o cuidado das pessoas, seja do indivíduo, da família ou comunidade, independente dos contextos e ambientes, durante todo o ciclo vital. Ela visa à manutenção da vida, a melhoria na Qualidade de vida, prevenindo doenças ou amenizando seus efeitos ermagem de forma independente" (5), além do seu enfoque na promoção da saúde.

Entretanto, também ficou evidente que os acadêmicos tinham uma idéia de um Enfermeiro "auxiliar de outros profissionais e com pouca autonomia”. Um dos sujeitos refereiu também Que ao ingressar no curso desconhecia as competências técnicas e científicas das diferentes categorias na enfermagem, ou seja, do Enfermeiro Que é um profissional de nível superior e, dos Técnicos e Auxiliares de Enfermagem, Que são profissionais de nível médio e, relatou também, Que desconhecia a existência de consultas de enfermagem, realizadas pelo Enfermeiro.

\section{A visão dos Acadêmicos a respeito do profissional Enfermeiro ao concluírem a Graduação}

Estes mesmos Acadêmicos, estando agora já na última fase ( $8^{\circ}$ semestre), e Quase finalizando o Curso de Graduação em Enfermagem, mantém a sua visão de Enfermeiro como sendo um "profissional voltado para o cuidado". As categorias Que emergiram dos dados referente à visão dos Acadêmicos em relação ao profisional Enfermeiro atualmente, ao serem formandos são: avanços e conQuistas, satisfação profissional e lacunas na profissão. A seguir, apresentaremos cada uma delas.

\section{Avanços e coneuistas}

Atualmente, para os próprios profissionais da saúde em geral, a prática social do enfermeiro é visibilizada como sendo um articular e integrador das ações de saúde. Destaca-se, pela capacidade de 


\begin{tabular}{|c|c|c|}
\hline Acadêmico & Ao ingressarem na Graduação & Ao concluírem a Graduação \\
\hline Acadêmico 1 & $\begin{array}{l}\text { Imaginava como sendo aquela pessoa que cuida de } \\
\text { outra, Que oferece carinho, conforto, apoio emocional, } \\
\text { além de oferecer apenas técnicas de enfermagem. No } \\
\text { entanto tinha uma idéia muito pequena do nosso } \\
\text { campo de trabalho, pois só conseguia imaginar esse } \\
\text { profissional exercendo sua profissão em hospitais ou } \\
\text { em postos de saúde, sempre trabalhando para outra } \\
\text { pessoa. }\end{array}$ & $\begin{array}{l}\text { Hoje, ao sair da faculdade, continuo com a mesma visão daQuele } \\
\text { profissional voltado para o cuidado. No entanto, com a ajuda da disciplina } \\
\text { optativa "Mercado de Trabalho", consigo enxergar um campo mais amplo } \\
\text { para atuarmos na nossa profissão, um campo mais diversificado, mais } \\
\text { autônomo, etc. Vale ressaltar Que não são todos os docentes Que me } \\
\text { proporcionaram isso, visto Que nossa graduação é totalmente voltada para } \\
\text { trabalharmos apenas no serviço primário ou terciário. }\end{array}$ \\
\hline Acadêmico 2 & $\begin{array}{l}\text { Profissional que presta atendimento indispensável em } \\
\text { saúde. Tinha uma visão limitada dos cenários de } \\
\text { atuação da categoria ao pensar apenas em Hospitais, } \\
\text { Clínicas e Centros de Saúde. }\end{array}$ & $\begin{array}{l}\text { Hoje percebo que a necessidade da existência do serviço do Enfermeiro(a) } \\
\text { está além do equivocado e retró grado pensamento de um profissional } \\
\text { institucionalizado que tem por único objetivo driblar enfermidades. Ele tem } \\
\text { inúmeras possibilidades de atuação e de objetivos. A diferença está na } \\
\text { vontade e na iniciativa de realizações permeadas de desejos por mudanças } \\
\text { Que ultrapassam as barreiras das limitaçôes e das desmotivaçôes. }\end{array}$ \\
\hline Acadêmico 3 & $\begin{array}{l}\text { A visão que tinha antes de ingressar na academia era } \\
\text { de um profissional cuidador, porém auxiliar de outros } \\
\text { profissionais e com pouca autonomia. Acreditava que } \\
\text { tínhamos como campo de trabalho, apenas o âmbito } \\
\text { hospitalar, saúde pública e "home care". }\end{array}$ & $\begin{array}{l}\text { Hoje vejo na enfermagem um profissional completo para atuar em todas as } \\
\text { áreas da saúde, com inúmeras opções de campo de trabalho. Tenho } \\
\text { orgulho da profissão Que irei exercer, tendo certeza Que a enfermagem é } \\
\text { uma profissão fundamental e insubstituível Quando trata-se de cuidado de } \\
\text { Qualidade. }\end{array}$ \\
\hline Acadêmico 4 & $\begin{array}{l}\text { Optei pela enfermagem no vestibular porque realmente } \\
\text { Queria atuar na área da saúde e escolhi o curso por } \\
\text { saber que o profissional de enfermagem está mais } \\
\text { próximo das pessoas e conseQuentemente cria um } \\
\text { vínculo maior com pacientes e família. }\end{array}$ & $\begin{array}{l}\text { Hoje penso que jamais faria outro curso, pois, me apaixonei pela } \\
\text { enfermagem. Nossa futura profissão possui muito potencial e capacidade } \\
\text { para consquistar grandes relações de cuidado. Entretanto, há muitas } \\
\text { decepçôes também, percebo nitidamente a invisibilidade, falta de } \\
\text { reconhecimento, de corporativismo e organização da profissão. Ainda } \\
\text { temos muito a conquistar e lutar! }\end{array}$ \\
\hline Acadêmico 5 & $\begin{array}{l}\text { Quando iniciei a graduação desconhecia em parte as } \\
\text { competências tanto técnicas Quanto científicas que } \\
\text { diferenciam o profissional de enfermagem graduado de } \\
\text { enfermagem dos outros profissionais que compóem a } \\
\text { equipe. Tinha uma vaga idéia em relação às rotinas de } \\
\text { um enfermeiro atuando em unidade hospitalar e na } \\
\text { saúde básica, desconhecia a existência das consultas } \\
\text { de enfermagem. No meu entender as possibilidades de } \\
\text { atuação do enfermeiro se restringiam a estes dois } \\
\text { campos, até mesmo porque o currículo atual é } \\
\text { concentrado exatamente nestas oportunidades. }\end{array}$ & $\begin{array}{l}\text { Por meio de profissionais e da disciplina Mercado de Trabalho, ministrada } \\
\text { no } 8^{\circ} \text { período da graduação, descobri uma profissão ampla e em constante } \\
\text { desenvolvimento. Serviços como o home care, mostram que o mercado } \\
\text { proporciona algo mais do que nos é apresentado. }\end{array}$ \\
\hline Acadêmico 6 & $\begin{array}{l}\text { Enfermeiro generalista, com ênfase em saúde pública. } \\
\text { Não tem a noção ou conhecimento sobre o seu } \\
\text { potencial e capacidade além das prerrogativas } \\
\text { estabelecidas pela instituição formadora. }\end{array}$ & $\begin{array}{l}\text { Enfermeiro generalista, com ênfase em saúde pública. Com pouco } \\
\text { conhecimento e nenhuma experiência Quanto à capacidade e possibilidades } \\
\text { de atuação do enfermeiro. Mas está plantada a semente da busca por novos } \\
\text { conhecimentos, capacidades e campos de atuação. A verdade é o produto } \\
\text { e a finalidade de uma universidade, mas ao invés disso, nos mostra a } \\
\text { verdade Que ela Quer Que enxerguemos. }\end{array}$ \\
\hline
\end{tabular}

\section{Quadro 1. A profissão do Enfermeiro(a) retratada pelos Acadêmicos de Enfermagem ao ingressarem no Curso de Graduação em Enfermagem e ao concluírem o Curso, levando em conta também, as discussões desencadeadas por meio da Disciplina Mercado de Trabalho em Enfermagem e novas modalidades de prestação de serviço.}

compreender o contexto social, "acolher e identificar-se com as necessidades e expectativas dos usuários da saúde, pela capacidade de interagir diretamente com o usuário, família e comunidade, bem como promover a interação destes com a equipe de saúde"(6).

Desta maneira evidencia-se um espaço amplo de atuação do Enfermeiro, Que vem sendo reconhecido pelos profissionais da saúde como um articulador nos serviços de saúde, Que envolve o contexto social mais amplo, a sua proximidade e interação com a clientela, e com inúmeras possibilidades de atuação, conforme as falas dos sujeitos a seguir:

Hoje vejo na enfermagem um profissional completo para atuar em todas as áreas da saúde, com inúmeras opções de campo de trabalho. (Acadêmico 3).

...com a ajuda da disciplina optativa "Mercado de Trabalho", consigo enxergar um campo mais amplo para atuarmos na nossa profissão, um campo mais diversificado, mais autônomo, etc. Vale ressaltar que não são todos os docentes que me proporcionaram isso... (Acadêmico I).

Por meio de profissionais e da disciplina Mercado de Trabalho, ministrada no $8^{\circ}$ período da graduação, descobri uma profissão ampla e em constante desenvolvimento. Serviços como o home care, mostram que o mercado proporciona algo mais do Que nos é apresentado (Acadêmico 5).

Hoje percebo Que a necessidade da existência do serviço do Enfermeiro(a) está além do equivocado e retrógrado pensamento de um profissional institucionalizado que tem por único objetivo driblar enfermidades. Ele tem inúmeras possibilidades de atuação e de objetivos. A diferença está na vontade e na iniciativa de 
realizações permeadas de desejos por mudanças Que ultrapassam as barreiras das limitações e das desmotivações (Acadêmico 2).

Assim, o empreendedorismo social não é uma ação Que simplesmente emerge do nada. Faz-se necessário uma construção mental de possibilidades que podem ser incentivadas desde a graduação, como também podem ser desencadeadas por fatores como, aQuisição de experiências que ultrapassam as possibilidades de crescimento profissional oferecidas, ou insatisfações referentes às atribuições profissionais, financeiras, dentre outras.

...está plantada a semente da busca por novos conhecimentos, capacidades e campos de atuação... (Acadêmico 6).

Por meio das falas citadas acima, ficou claro Que é necessário incentivar e despertar nos acadêmicos, futuros enfermeiros, desde a graduação, as diversas opções e modalidades de atuação do profissional enfermeiro, bem como a sua autonomia para o trabalho, o Que certamente irá contribuir para um maior reconhecimento, valorização, melhora da auto-estima dos enfermeiros e maior visibilidade da profissão, bem como, de reconhecer o cuidado empreendedor como um compromisso social no exercício da cidadania em busca do viver com mais saúde.

\section{Satisfação profissional}

Os acadêmicos de enfermagem, embora ainda não exercendo a profisão de Enfermeiro, sentem orgulho da profissão Que escolheram e tem consciência da capacidade e do potencial do Enfermeiro e das conQuistas Que poderá alcançar na profissão.

... Tenho orgulho da profissão Que irei exercer, tendo certeza Que a enfermagem é uma profissão fundamental e insubstituível Quando trata-se de cuidado de Qualidade (Acadêmico 3).

Hoje penso Que jamais faria outro curso, pois, me apaixonei pela enfermagem. Nossa futura profissão possui muito potencial e capacidade para conQuistar grandes relações de cuidado... (Acadêmico 4).

\section{Lacunas na profissão}

Um marco imponente nas organizações dos serviços de saúde, na assistência prestada e no próprio senso comum da população é o modelo biomédico de atenção à saúde. Tudo isto porque o curativismo ainda existe como foco principal, senão único, na atenção à saúde. Por este motivo, ainda hoje, nos deparamos com uma assistência prestada em função do diagnóstico médico de corpos doentes, mesmo Que muito se tenha discutido sobre a importância do trabalho interdisciplinar da equipe de saúde para a constituição de um modelo centrado no ser humano, a fim de nortear o planejamento e a execução das ações de saúde ${ }^{(2)}$.

Assim, o cotidiano visto na saúde é uma assistência em prol da Queixa-conduta. Nesse sentido, o trabalho da enfermagem acompanha a evolução desse setor e, da mesma forma, continua realizando seu trabalho em função de tratar a doença, da Qual o médico é o protagonista ${ }^{(2)}$. Mesmo com a Carta de Otawa, onde o conceito de saúde ultrapassa o corpo físico e passa a considerar também o contexto social, ambiental, político e econômico do indivíduo ${ }^{(10)}$, a assistência em saúde continua voltada em prol da Queixa-conduta. Nesse contexto, a atuação da enfermagem acaba por apenas oferecer sustentação às práticas médicas, constituindose de um trabalho complementar na hegemonia médica e, consecüentemente, sendo assim reconhecido na sociedade. Os profissionais de enfermagem sempre admirados pela caridade, acabam por sustentar, diversas vezes, o mito da doação vocacional como alternativa para garantir prestígio social(2).

Neste sentido, o trabalho do Enfermeiro acaba sendo visto como um trabalho complementar, subordinado aos profissionais da medicina, voltado para a caridade, e com pouca ou nenhuma autonomia, o Que reflete na invisibilidade da profissão, conforme a fala do sujeito a seguir:

...Entretanto, há muitas decepções também, percebo nitidamente a invisibilidade, falta de reconhecimento, de corporativismo e organização da profissão. Ainda temos muito a conquistar e lutar! (Acadêmico 4).

A visibilidade do enfermeiro se apresenta das formas mais diversas possíveis. Enquanto Que para alguns o enfermeiro é representado "como auxiliar de médico", para outros lembra uma "figura vestida de branco" ou um "profissional desvalorizado", pela baixa remuneração, "como um articulador dos serviços de saúde", entre outros.

Assim, de maneira geral, há uma prática comum da população de nomear como enfermeira Qualeuer pessoa vestida de branco Que não for médico e Que esteja atuando em instituições de saúde. Essa prática certamente representa um reflexo da representação na auto-imagem e na auto-(des)valorização dos profissionais de enfermagem em relação ao seu trabalho e função social ${ }^{(11)}$.

A enfermeira tem sua imagem identificada pela sociedade, composta de estereótipos, evidenciando o desconhecimento sobre a sua atuação, ou caráter depreciativo em relação a essa profissão. A figura da enfermeira é identificada com distorções e, muitas vezes, como sendo um profissional desvalorizado socialmente, devido à imagem de Que a profissão tem baixa remuneração e é subordinada a outros profissionais, especialmente à medicina ${ }^{(12)}$.

Vários pesquisadores da área da enfermagem têm demonstrado preocupação com a temática da visibilidade da profissão e vem mostrando, por meio de suas investigações, Que tanto os avanços como também as lacunas necessitam ser supridas para sustentar e fomentar a profissão como ciência e arte, conforme mostram as reflexões a seguir.

Para alguns autores, a enfermagem precisa ocupar espaços e ter o reconhecimento enQuanto uma das profissões essenciais da saúde. Necessita de uma agenda política específica Que expresse os vários aspectos constitutivos de uma profissão, isto é, o saber específico, o mercado de trabalho, a forma de organização, Que apontem sobre a necessidade da categoria participar mais efetivamente das diferentes iniciativas Que dizem respeito à saúde, inclusive, as empreendidas no âmbito internacional, no sentido de ampliar a visibilidade do saber e do fazer em enfermagem ${ }^{(13,14)}$.

Além dos elementos já pontuados, o enfermeiro tem a necessidade de mergulhar na realidade do indivíduo, de estabelecer vínculos de solidariedade e de ver as coisas acontecerem da forma mais rápida e resolutiva possível(6). 
Os profissionais de enfermagem devem discutir e trabalhar no intuito de construir, coletivamente, uma profissão mais influente, comprometida e ativa nas decisões de políticas públicas, sociais e institucionais. Buscar uma profissão mais atuante, Que tenha o compromisso social necessário para conQuistar maior autonomia, a fim de realmente trabalharmos com a promoção da saúde, em defesa da vida, e mais do Que isso, possibilitar espaços Que dêem visibilidade à profissão, garantindo assim, a chance de novas imagens da enfermagem Que reflitam o seu verdadeiro potencial perante a sociedade ${ }^{(2)}$.

Infelizmente, o que se observa em nossa realidade é a supremacia da atuação institucionalizada, causando delimitação da atuação profissional, em detrimento do estímulo à atuação criativa para o aperfeiçoamento profissional. E isso é uma deficiência Que está presente desde a formação do enfermeiro na graduação, como aparece nas falas a seguir:

...nossa graduação é totalmente voltada para trabalharmos apenas no serviço primário ou terciário (Acadêmico I).

Enfermeiro generalista, com ênfase em saúde pública. Com pouco conhecimento e nenhuma experiência Quanto à capacidade e possibilidades de atuação do enfermeiro... (Acadêmico 6).

...A verdade é o produto e a finalidade de uma universidade, mas ao invés disso, nos mostra a verdade que ela quer que enxerguemos (Acadêmico 6).

Como resultado, na prática, há poucos Enfermeiros Que encontram-se firmemente alicerçados em ações diferenciadas. Pelo contrário, muitos escolhem vínculos profissionais Que ofereçam estabilidade, sem riscos ou exigências, além de mecanizadas.

Não se trata de promover a mercantilização do trabalho do enfermeiro, mas sim, de despertar para o empreendedorismo social como competência política de articulação entre os diferentes segmentos sociais em prol da promoção de melhores práticas no cuidado à saúde da população.

Entretanto, sabemos Que na missão das universidades no Que segue como estratégia, além do ensino e assistência - não devendo existir o prejuízo de uma das partes em relação às outras - há a formação de trabalhadores Que tenham conhecimentos das inúmeras alternativas de atuação profissional, além das tradicionais, oferecendo ferramentas para o crescimento e sobrevivência profissional com abrangência, visibilidade e impacto. Para tanto, faz-se necessária a contribuição da academia em fornecer informação e estímulo aos discentes para aquisição de competências Que impulsionem o desenvolvimento de atribuições em QualQuer nível de atuação, com vistas à formação de profissionais empreendedores.

Hoje em dia, o cuidado torna-se cada vez mais essencial, frente ao surgimento de novas formas de adoecer, devido ao aumento de portadores crônicos e debilitantes e a tendência de inversão da pirâmide populacional. Em tempos de necessidades complexas, a procura pelos serviços de enfermagem é enorme e só tende a crescer ${ }^{(5)}$.
Porém, perpetua-se o antigo espaço de atuação incumbido ao enfermeiro, no Qual a enfermagem ainda está limitada a discussões fechadas, em que continua desconhecida a riqueza das variadas visões sobre as práticas de saúde exercidas por ela. No entanto, para alcançarmos o reconhecimento da profissão e reconstruirmos as exigências sociais Que nos sustentam, é necessário estabelecer uma formação criadora de identidade e representatividade visível aos diferentes campos sociais e participarmos das organizações das políticas de saúde, construindo o processo de ser enfermagem ${ }^{(2)}$.

Esta reflexão nos remete a afirmativa de Que: "a primeira tarefa das enfermeiras é ajudar o público a construir um significado autêntico para a palavra 'enfermeira' Que transmita a riQueza, a singularidade e a indispensabilidade da enfermagem em todo seu espectro de trabalho"(15).

Sob esta ótica é Que construímos o presente artigo, com o intuito de estimular acadêmicos e profissionais de enfermagem a modificar as imagens não condizentes com nossa profissão e alcançar atitudes estratégicas que re-signifieuem o imaginário social. Desta maneira, certamente atingiremos maior visibilidade e ascensão profissional.

\section{CONCLUSÃO}

A visibilidade do enfermeiro é conquistada pela busca das possibilidades interativas e associativas de contribuição social, nos diferentes espaços e campos de atuação, no sentido de ampliar e dar a conhecer o seu campo de intervenção. Assumindo um lugar cada vez mais distinto, a enfermagem vem se afirmando como uma profissão em crescimento e inserida no processo de mudanças nos diferentes campos de atuação, na área da saúde.

Os Acadêmicos vêem o Enfermeiro como sendo um profissional voltado para o cuidado. As categorias Que emergiram dos dados referente à visão dos Acadêmicos de Enfermagem em relação ao profisional Enfermeiro atualmente, ao serem formandos são: avanços e conQuistas, satisfação profissional e lacunas na profissão.

Vivenciamos ainda a desvalorização profissional na enfermagem e representamos, muitas vezes, um grupo marginalizado. Todavia, para Que seja possível transformar esta realidade, é essencial que os próprios profissionais se responsabilizem pelas suas ações, se desacomodem e enfrentem os desafios, procurando apropriar-se das suas competências, de modo a intervir de forma pró-ativa nas diferentes demandas sociais. Isso implica na articulação de competências com evidência a nível técnico, científico e relacional, o Que concorre para a representação social da profissão. A visibilidade profissional constrói-se, nesse sentido, a partir das atitudes individuais Que formam o coletivo, e Que, por sua vez, se refletem nos diferentes espaços e campos de atuação profissional.

É fundamental despertar a visão empreendedora social do Enfermeiro desde a graduação para Que os acadêmicos adQuiram uma visão mais ampliada da profissão de enfermagem, com competência política, na possibilidade de atuação Que vai muito além do trabalho institucionalizado, porém não mercantilizado, além da tarefa de motivar e criar estratégias para Que a profissão conQuiste mais voz e vez nos diversos campos de atuação profissional. 


\section{REFERÊNCIAS}

I. Costa AB. O Desenvolvimento Econômico na Visão de Joseph Schumpeter. São Leopoldo: Unisinos; 2006.

2. Pai DD, Schrank G, Pedro ENR. O enfermeiro como ser sóciopolítico: refletindo a visibilidade da profissão do cuidado. Acta Paul Enferm 2006; 19(1): 82-7.

3. Gomes NCS. A Visibilidade da Enfermagem: articulação de competências científicas, técnicas e relacionais de um enfermeiro de Cuidados Intensivos. [citado em: 06 out 2008]. Disponível em: http://rebentaabolha.blogs.sapo.pt/7 163.html.

4. Kemmer LF, Silva MJP. A visibilidade do enfermeiro segundo a percepção de profissionais da comunicação. Rev Latino-am Enfermagem 2007; 15(2): 191-8

5. Fahl LG. Dando visibilidade à atuação do enfermeiro pela internet: um estudo de sua influência sobre as representações sociais do adolescente [tese]. São Paulo: Escola de Enfermagem, Universidade de São Paulo; 2007.

6. Backes DS. Vislumbrando o cuidado de enfermagem como prática social empreendedora [tese]. Florianópolis: Programa de Pós-Graduação em Enfermagem, Universidade Federal de Santa Catarina; 2008

7. Erdmann AL, Backes, DS. Formación de emprendedor en el oficio de enfermera: Promover capacidades y aptitudes políticas sociales. Enfermería Global 2008; 5( I6): 32-43.
8. Erdmann AL. Mercado de Trabalho em Enfermagem e novas modalidades de prestação de serviço. Disciplina: NFR 5169 do Programa de Enfermagem da Universidade Federal de Santa Catarina. Florianópolis: UFSC; 2007.

9. Bardin L. Análise de conteúdo. 3ª ed. Lisboa: Persona; 1995.

10. World Health Organization (WHO). Carta de Ottawa, 1986. In.: Ministério da Saúde (BR. FIOCRUZ. Promoção da Saúde: Cartas de Ottawa, Adelaide, Sundsvall e Santa Fé de Bogotá. Brasília: Ministério da Saúde; 2006.

I I. Oliveira BGRB. A passagem pelos espelhos: a construção da identidade profissional da enfermeira. Texto Contexto Enferm 2006; 15(1): 60-7.

12. Nauderer TM, Lima MADS. Imagem da enfermeira: revisão da literatura. Rev Bras Enferm 2005; 58(1): 74-7.

13. Bertolozzi MR. Saúde internacional: uma das possibilidades de atuação da enfermagem no campo da saúde coletiva. Rev Latinoam Enfermagem 1996; 4(1): 87-95.

14. Machado MH. A profissão de enfermagem no século XXI. Rev Bras Enferm 1999; 52(4): 589-95.

15. Buresh B, Gordon S. Do silêncio à voz. Coimbra: Ariadne, 2004. 
